\title{
Description of Hemoproteins and Elemental Homeostasis in Brain Tumors
}

\author{
E. I. Erlykina1, L. M. Obukhova1, I. A. Medyanik ${ }^{1}$, K. S. Yashin'1, V. G. Pimenov' \\ I. I. Evdokimov' , 0. V. Barinova1, A. B. Yazykova ${ }^{*}$ \\ ${ }^{1}$ Federal State Budgetary Educational Institution of Higher Education "Privolzhsky Research Medical University" of the Ministry \\ of Health of the Russian Federation, Nizhny Novgorod, Russia \\ ${ }^{2}$ FPFIS G.G. Devyatykh Institute of Chemistry of High-Purity Substances of RAS, Nizhny Novgorod, Russia \\ Email: biochem@pimunn.ru, pimenov@Ihps.nnov.ru, *poet509@yandex.ru
}

How to cite this paper: Erlykina, E.I., Obukhova, L.M., Medyanik, I.A., Yashin, K.S., Pimenov, V.G., Evdokimov, I.I., Barinova, O.V. and Yazykova, A.B. (2018) Description of Hemoproteins and Elemental Homeostasis in Brain Tumors. Journal of Biosciences and Medicines, 6, 89-96. https://doi.org/10.4236/jbm.2018.65010

Received: March 29, 2018

Accepted: May 21, 2018

Published: May 24, 2018

Copyright $\odot 2018$ by authors and Scientific Research Publishing Inc. This work is licensed under the Creative Commons Attribution International License (CC BY 4.0).

http://creativecommons.org/licenses/by/4.0/

(c) (i) Open Access

\begin{abstract}
The role of element homeostasis in neoplastic disease pathogenesis is beyond question. The imbalance of trace elements precisely underlies the initiation and promotion of tumor pathology. The aim of the study was to investigate blood and tissue macroelements, microelements and hemoproteins level in brain tumors and their intermolecular interactions. Samples of blood and brain tumor tissues were investigated. Detection of myoglobin level was implemented by the reaction of passive hemagglutination and immunoturbidimetric test. Catalase activity was determined by the method of Beer and Sizer. Free radical activity was determined by the method of induced biochemiluminescence. Microelements level was investigated by usage of atomic emission spectrometry. To build the networks of studied hemoprotein interactions with signaling pathways of proteins, expressed in brain tumors, molecular interaction databases (STRING, BioGrid) were used. Modern databases of signaling pathways (KEGG) suggest that in normal cells hypoxia can lead to HIF-1A protein synthesis. ROS synthesis inhibits the PHD enzyme and triggers the release of calcium ions, and increases proliferation. Calcium ions are triggering factor of apoptosis and cell proliferation. Myoglobin can possibly be the cell adaptation factor towards hypoxia, oxidative stress and element homeostasis violation, and myoglobin level decreasing can additionally stimulate proliferation, by apoptosis inhibition.
\end{abstract}

\section{Keywords}

Brain Tumors, Elemental Homeostasis, Hypoxia, Intermolecular Interactions, Signaling Pathways 


\section{Introduction}

Primary tumors of central nervous system are a rare group of diverse tumors that account for less than $2 \%$ of all tumors, but are the fourth most common cause of cancer death. Despite of advances in neurosurgery, the development of intraoperative navigation, as well as chemo and radiation therapy, treatment of primary central nervous system tumors is still insufficiently effective. The average life-expectancy of those patients after surgery and following chemotherapy and radiation therapy is 14 and 25 months for the glioblastoma multiforme (GBM) and anaplastic astrocytoma respectively. It is also known, that the 5-year survival rate for intracranial glioblastoma multiforme (GBM) does not exceed $10 \%$ [1]. The role of element homeostasis in neoplastic disease pathogenesis is beyond question [2]. The imbalance of trace elements precisely underlies the initiation and promotion of tumor pathology, not only via nuclear and mitochondrial DNA metabolism modulation and reparation, but also through changes in various enzymatic and protein molecules, immune cells and antioxidant activity [3]. Catalase is considered to be one of the main antioxidant enzymes, which belongs to class Oxidoreductases and represents a hemoprotein consisting of 4 subunits. This hemoprotein catalyzes hydrogen peroxide decomposition, protecting the cell from oxidative stress. Catalase can also defend the tumor cells from apoptosis. Catalase has been suggested to synthesize on the tumor cell membrane surface and so this enzyme decomposes hydrogen peroxide, interferes with $\mathrm{HOCl}$ synthesis, inactivates $\mathrm{HOCl}$ and $\mathrm{NO}$, which are the trigger factors of tumor apoptosis [4]. Myoglobin, also belonging to hemoproteins, ensures reversible binding with oxygen, as well as oxygen storage and transport to the oxidative system cells from hemoglobin. Myoglobin has been reported to reveal in non-muscle tissue too, under anaerobic conditions [5]. Myoglobin high level has been revealed [6] in malignant tumors of human epithelial tissues (breast cancer, ovarian carcinoma, colorectal cancer) at the early stages of the disease development. Myoglobin tumor-suppressing role at the expense of mitochondrial activity inhibition is now a subject-matter of the discussion [7].

In the present study, the aim was to investigate blood and tissue macroelements, microelements and hemoproteins level in brain tumors, as well as their intermolecular interactions.

\section{Materials and Methods}

\subsection{Sample Preparation}

Samples of blood and brain tumor tissues were taken from 12 patients with malignant brain tumors (glioma, glioblastoma, astrocytoma), and among them there were 6 men and 6 women, aged 39 to $53 ; 7$ patients with benign brain tumor (meningioma, subependymoma), among them there were 3 women and 4 men aged 37 to 59 , prior to treatment.

Samples of tissues, taken from 7 patients died as a result of trauma related to road traffic accident, without connection to head and brain injury (time of 
death: up to $10 \mathrm{~h}$ ), among them there were 3 men and 4 women, aged 36 - 47, as well as samples of blood, taken from 10 healthy people ( 5 men and 5 women, aged 35 - 65) were used as the control.

Blood sample selection and sampling technique were conducted according to the Standard protocol, approved by the Ministry of Health. Blood and tissue samples were collected in plain sterile tube to yield serum for estimation of parameters investigated. Tissue samples were taken at the time of surgical treatment strictly from tumor or operational zone with all necessary precautions according to the Standard protocol. Blood and tissue samples, for various reasons unsuitable for the study, were excluded.

\subsection{Myoglobin Detection}

Detection of myoglobin level was implemented by 2 methods: in the reaction of passive hemagglutination with the usage of erythrocyte antigen "DS-ERYTHRO-MYOGLOBIN" made by NPO "Diagnostic systems" and by immunoturbidimetric test using "DiaSys Diagnostic Systems GmbH" sets (fixed-time method based on photometric measurement of the antigen-antibody reaction between antibodies against human myoglobin immobilized on latex particles and myoglobin, presented in the sample) [8] [9].

\subsection{Catalase Detection}

Catalase activity in brain and erythrocytes was determined by the method of Beer and Sizer (1952), based on optical density decreasing in the region of hydrogen peroxide light absorption at $240 \mathrm{Hm}$. So long as catalase is an enzyme of antioxidant defense system, free radical activity of blood plasma by the method of induced biochemiluminescence was determined at the same time [10].

\subsection{Statistical Data Processing}

Statistical data processing was performed using STATISTICA Base software (StatSoft Inc). For statistical analysis non-parametric criteria (Mann Whitney U-test, Kolmogorov-Smirnov test) were used. To analyze the correlation dependence, non-parametric criterion (Pearson criterion) was implemented. To build the networks of studied hemoproteins interactions with signaling pathways of proteins, expressed in brain tumors, to create a visualization model of protein-protein interactions, molecular interaction databases (STRING, BioGrid) were used.

\section{Results}

In our study a significant increase (more than 7 times) of calcium concentration in blood and brain tumor tissue were detected, compared with healthy people. In malignant brain tumors magnesium level was reduced in 1.7 times in comparison with healthy brain tissue. A statistically significant correlation between catalase activity and magnesium level $(r=0.559)$, as well as the content of myoglobin and magnesium level $(r=0.506)$ was revealed $(\mathrm{p}<0.05)$. 
Analysis of trace elements in tumor tissue revealed their significant increase compared with the brain tissue of healthy people. Iron, zinc and copper level were 3.1, 3.2 and 10 times increased respectively. In the blood plasma multidirectional dynamics of changes in the levels of these trace elements was observed. Analysis of microelements level in blood plasma showed a significant decrease in the concentration of $\mathrm{Cu}$ (per 49\%), $\mathrm{Zn}$ (2.5 - 5 times), and the increase in content of $\mathrm{Fe}$ (up to $45 \%$ ). In the course of the study catalase activity in tumor tissue was found to be $22 \%$ higher in malignant $(18.87 \mathrm{~mm} / \mathrm{l})$ and benign $(18.42 \mathrm{~mm} / \mathrm{l})$ brain tumors compared with the control group $(14.37 \mathrm{~mm} / \mathrm{l})$. The free radical activity in the tumor tissues was significantly increased in malignant $(6.42 \mathrm{mV})$ and benign $(3.85 \mathrm{mV})$ brain tumors compared with the control group $(1.5 \mathrm{mV})$. Catalase activity in erythrocytes was significantly lower in patients with brain tumors compared to control group $(15.24 \mathrm{~mm} / \mathrm{l})$. In patients with malignant brain tumors, blood catalase activity decreased more significantly $(4.47 \mathrm{~mm} / \mathrm{l})$, more than 3 times than in benign tumors $(10.98 \mathrm{~mm} / \mathrm{l})$, where decreased 1.4 times. Free radical activity of blood plasma, on the contrary, increased in malignant brain tumors $(18.96 \mathrm{mV})$ compared to healthy people $(1.25 \mathrm{mV})$ and people with benign tumors ( $6.96 \mathrm{mV}$ ), more than 15 and 2.5 times, respectively. In the investigation of healthy people brain tissue (control group) myoglobin was not detected. At the same time myoglobin was determined in large concentrations in brain tumor tissue of patients with benign and malignant tumors: in malignant tumors, its concentration was higher $(74.86 \pm 1.12 \mathrm{ng} / \mathrm{ml})$ than in benign tumors $(24.36 \pm 3.59 \mathrm{ng} / \mathrm{ml})$. Blood plasma myoglobin level in brain malignant tumors (46 $\mathrm{ng} / \mathrm{ml}$ ) was $24 \%$ higher than those values in healthy individuals of the control group (15 ng/ml). The amount of hemoprotein in plasma in benign tumors is not significantly different from the control $(17 \mathrm{ng} / \mathrm{ml})$.

\section{Discussion}

In our study a significant increase (more than 7 times) of calcium concentration in blood and brain tumor tissue were detected, compared with healthy people. Hypercalcemia in brain tumors is a well-known fact [11]. Inositol-3-phosphate signaling system is dominant for maintaining the proliferative activity of embryonic cells, so the increase of calcium concentration, which is a secondary messenger, leads to the activation of this system [12]. In malignant brain tumors magnesium level was reduced, but increased magnesium level has been shown to stabilize and activate hypoxia-inducible factor $1 \alpha$ (HIF-1 $\alpha$ ), which, in turn, reduces hypoxia-induced effects in the cell [13] [14]. HIF-1 $\alpha$ has been shown as a master regulator of hypoxic response [13]. A correlation between catalase activity and magnesium level as well as the content of myoglobin and magnesium level possibly reflects magnesium role in antioxidant system, as long as magnesium is essential for glutathione synthesis reaction, so it's deficiency increases free radical formation. It has also been shown, that hypomagnesemia suppresses reactive oxygen species (ROS)-induced HIF-1 $\alpha$ activity [15]. 
The free radical activity in the tumor tissues was significantly increased in malignant and benign brain tumors compared with the control group. Probably, the increase of catalase activity in brain tumor tissues could indicate an increased concentration of peroxides, which need to be inactivated by this enzyme [16]. The decrease of catalase activity in erythrocytes can be possibly associated with a reduction in the generation of $\mathrm{H}_{2} \mathrm{O}_{2}$ in the blood in the neoplastic process progression [17]. In the investigation of healthy people brain tissue (control group) myoglobin was not detected. At the same time myoglobin was determined in large concentrations in brain tumor tissue of patients with benign and malignant tumors: in malignant tumors, its concentration was higher than in benign tumors. This is probably due to hypoxia inducible expression of myoglobin. It is known that myoglobin is detected in tissues in hypoxia: the expression of this hemoprotein in various tissues is shown, including brain and liver, in chronic hypoxia [18]. So, [5] showed a high level of myoglobin in malignant tumors of epithelial tissues (breast cancer, ovarian cancer, colon cancer) at the earliest stages of the disease. In malignant human cells myoglobin is induced by a variety of signals associated with tumor progression, including mitogenic stimuli, oxidative stress, and hypoxia. Probably, the enhanced expression of myoglobin in tumor tissues is due to the effect of hypoxia-inducible factor (HIF). It is known that HIF-1a is a mediator of hypoxic cell damage, particularly in the brain [19]. In model experiments on animals exposed to hypoxia, global cerebral ischemia and focal ischemia increased expression of HIF-1a gene has been shown.

Modern databases of signaling pathways (KEGG) suggest that in normal cells the conditions of hypoxia can lead to HIF-1A protein synthesis. Besides, it is known, that [18] chronic intermittent hypoxia $(\mathrm{CIH})$ induces reactive oxygen species (ROS) generation, thereby increasing HIF- $1 \alpha$ expression.

Detected reduced magnesium content in brain cancer cells can lead to decreasing of HIF- $1 \alpha$ activation, and probably, can serve as initiating agent for pathologic proliferation development. This factor, together with the protein p53 leads to synthesis and activation of proteins p21/27, which in turn inhibits CDK4/6 and leads to proliferation decrease. Intermittent hypoxia, leading to activation of the NOX enzyme, activates ROS synthesis, which inhibits the PHD enzyme and triggers the release of calcium ions. Calcium ions can be a triggering factor of two fundamental processes, apoptosis (often implemented under normal conditions) and cell proliferation via the Ras protein.

In glioma activation of protein synthesis of EGFR was shown, which, presumably, dramatically increases the release of calcium and thus activates the Ras protein, triggering uncontrolled proliferation. This effect may be exacerbated by the effects of ROS on the release of calcium ions (Figure 1). There is evidence that under hypoxic conditions the cell produces myoglobin, which inactivates tumor growth and represents a factor of the cells adaptation to hypoxia. According to the literature a hypothetical relationship with $\mathrm{MB}$ is noted, as well as the expression of catalase, reduction of free radicals and oxidative stress [15] [17] [20]. 


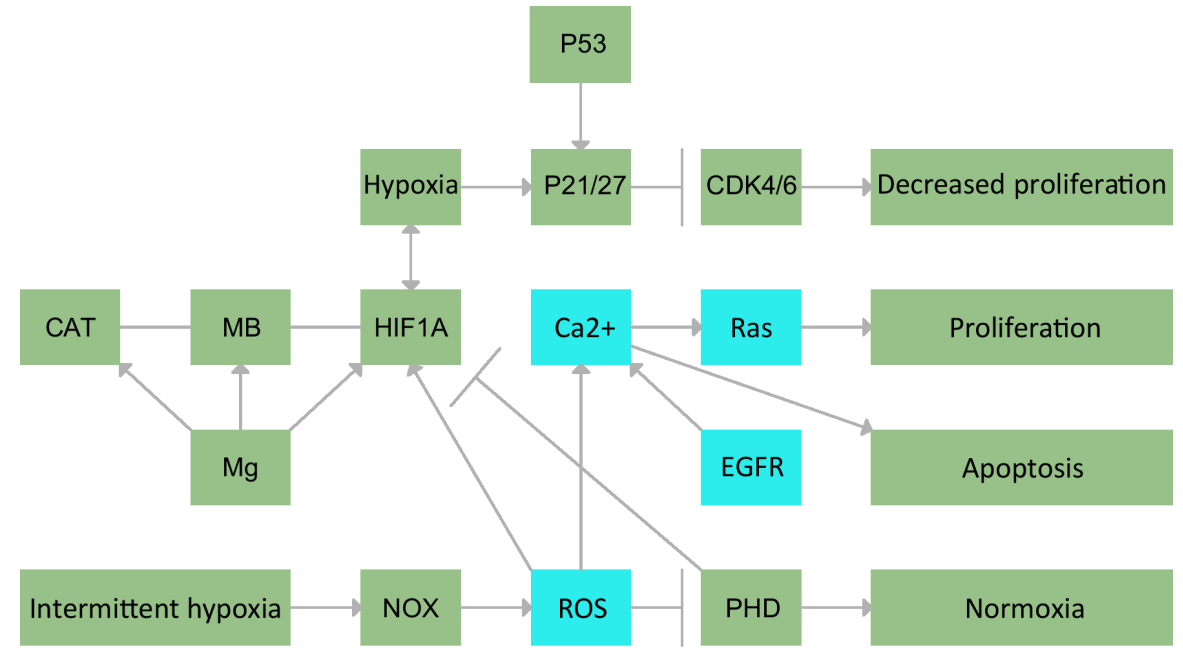

Figure 1. Network of protein signaling pathways of cell proliferation, active in the formation of brain tumors, with the participation of catalase, myoglobin and magnesium.

\section{Conclusions}

This is one of the first studies to have examined intermolecular relationships between microelements, hemoproteins and antioxidant enzymes in gliomas.

In hypomagnesemia, observed in cancer cells, HIF- $1 \alpha$ stabilization and activation by ROS is violated, and that leads to activation of cell pathological proliferation. Under the circumstances, increased Ca concentration via Ras-way activation leads to cell proliferation activation, more aggravating the situation.

Combined disruption of mineral homeostasis and hypoxia, found in the present study, also can serve as factors, stimulating cell proliferation. Established increasing of hemoproteins activity, such as catalase and myoglobin, can possibly be considered as adaptation factor towards hypoxia, oxidative stress and element homeostasis violation.

\section{Ethical Statement}

Each sample collection obtained approval from the University Research Ethics Review Committee and a local institutional review board or ethics committee for specimen collection and archiving of clinical materials. Specimens are unlinked to personal identifiers so that sera cannot be traced to individual patients. The protocol for the laboratory-based evaluation of samples was approved by the University Research Ethics Review Committee. Patient informed consent statement was obtained.

\section{References}

[1] Fazeny-Dorner, B., Wenzel, C., Veitl, M., Piribauer, M., Rossler, K. and Dieckmann, K. (2003) Survival and Prognostic Factors of Patients with Unresectable Glioblastoma Multiforme. Anti-Cancer Drug, 14, 305-312. https://doi.org/10.1097/00001813-200304000-00008

[2] Gresner, P., Gromadzinska, J., Jablonska, E., Kaczmarski, J. and Wasowicz, W. 
(2009) Expression of Selenoprotein-Coding Genes SEPP1, SEP15 and hGPX1 in Non-Small Cell Lung Cancer. Lung Cancer, 65, 34-40. https://doi.org/10.1016/j.lungcan.2008.10.023

[3] Valko, M., Rhodes, C.J., Moncol, J., Izakovic, M. and Mazur, M. (2006) Free Radicals, Metals and Antioxidants in Oxidative Stress-Induced Cancer. Chemico-Biological Interactions, 160, 1-40. https://doi.org/10.1016/j.cbi.2005.12.009

[4] Georg, B. (2015) Increasing the Endogenous NO Level Causes Catalase Inactivation and Reactivation of Intercellular Apoptosis Signaling Specifically in Tumor Cells. Redox Biology, 6, 353-371. https://doi.org/10.1016/j.redox.2015.07.017

[5] Kanatous, S.B. and Mammen, P.P.A. (2010) Regulation of Myoglobin Expression. Journal of Experimental Biology, 213, 2741-2747.

https://doi.org/10.1242/jeb.041442

[6] Flonta, S., Arena, S., Pisacane, A., Michieli, P. and Bardelli, A. (2009) Expression and Functional Regulation of Myoglobin in Epithelial Cancers. American Journal of Pathology, 175, 201. https://doi.org/10.2353/ajpath.2009.081124

[7] Kristiansen, G., Hu, J., Wichmann, D., Stiehl, D.P., Rose, M., Gerhardt, J., Bohnert, A., ten Haaf, A., Moch, H., Raleigh, J., Varia, M.A., Subarsky, P., Scandurra, F.M., Gnaiger, E., Gleixner, E., Bicker, A., Gassmann, M., Hankeln, T., Dahl, E. and Gorr, T.A. (2011) Endogenous Myoglobin in Breast Cancer Is Hypoxia-Inducible by Alternative Transcription and Functions to Impair Mitochondrial Activity: A Role in Tumor Suppression? The Journal of Biological Chemistry, 286, 43417-434128. https://doi.org/10.1074/jbc.M111.227553

[8] Mair, J., Artner-Dworzak, E., Lechleitner, P., Morass, B., Smidt, J., Wagner, I., et al. (1992) Early Diagnosis of Acute Myocardial Infarction by a Newly Developed Rapid Immunoturbidimetric Assay for Myoglobin. British Heart Journal, 68, 462-468. https://doi.org/10.1136/hrt.68.11.462

[9] Zaninotto, M., Altinier, S., Lachin, M., Celegon, L. and Plebani, M. (1999) Strategies for the Early Diagnosis of Acute Myocardial Infarction Using Biochemical Markers. American Journal of Pathology, 111, 399-405. https://doi.org/10.1093/ajcp/111.3.399

[10] Erlykina, E.I., Kopytova, T.V., Alyasova, A.V., Gorshkova, T.N., Terentiev, I.G., Pimenov, V.G., Evdokimov, I.I. and Obukhova, L.M. (2013) Integral Analysis of Blood Plasma Biochemical Parameters as an Optimizing Diagnostic Technique of Epithelial Tissue Malignant Neoplasms. Modern Technologies in Medicine, 5, 51-55.

[11] Meng, Q.H. and Wagar, E.A. (2014) Laboratory Approaches for the Diagnosis and Assessment of Hypercalcemia. Critical Reviews in Clinical Laboratory Sciences, 20, $1-13$.

[12] Vivanco, I. and Sawyers, C.L. (2002) The Phosphatidylinositol 3 Kinase AKT Pathway in Human Cancer. Nature Reviews. Cancer, 2, 489-501. https://doi.org/10.1038/nrc839

[13] Huang, C.Y., Hsieh, Y.L., Ju, D.T., Lin, C.C., Kuo, C.H., Liou, Y.F., Ho, T.J., Tsai, C.H., Tsai, F.J. and Lin, J.Y. (2015) Attenuation of Magnesium Sulfate on $\mathrm{CoCl}_{2}$-Induced Cell Death by Activating ERK1/2/MAPK and Inhibiting HIF-1 $\alpha$ via Mitochondrial Apoptotic Signaling Suppression in a Neuronal Cell Line. The Chinese Journal of Physiology, 58, 244-253. https://doi.org/10.4077/CJP.2015.BAD296

[14] Lecuyer, M., Rubio, M., Chollat, C., Lecointre, M., Jégou, S., Leroux, P., Cleren, C., Leroux-Nicollet, I., Marpeau, L., Vivien, D., Marret, S. and Gonzalez, B.J. (2017) Experimental and Clinical Evidence of Differential Effects of Magnesium Sulfate on 
Neuroprotection and Angiogenesis in the Fetal Brain. Pharmacology Research \& Perspectives, 5, No. 4. https://doi.org/10.1002/prp2.315

[15] Torii, S., Kobayashi, K., Takahashi, M., Katahira, K., Goryo, K., Matsushita, N., Yasumoto, K., Fujii-Kuriyama, Y. and Sogawa, K. (2009) Magnesium Deficiency Causes Loss of Response to Intermittent Hypoxia in Paraganglion Cells. The Journal of Biological Chemistry, 284, 19077-19089. https://doi.org/10.1074/jbc.M109.004424

[16] Popov, B., Gadjeva, V., Valkanov, P. and Tolekova, A. (2000) Lipid Peroxidation, Superoxide Dismutase and Catalase Activities in Brain Tumor Tissues. Archives of Physiology and Biochemistry, 111, 455-459. https://doi.org/10.3109/13813450312331342328

[17] Liou, G.-Y. and Storz, P. (2010) Reactive Oxygen Species in Cancer. Free Radical Research, 44, 479-496. https://doi.org/10.3109/10715761003667554

[18] Ke, Q.D. and Max, C. (2006) Hypoxia-Inducible Factor-1 (HIF-1). Molecular Pharmacology, 70, 1469-1480. https://doi.org/10.1124/mol.106.027029

[19] Fraser, J., de Mello, L.V., Ward, D., Rees, H.H., Williams, D.R., Fang, Y., Brass, A., Gracey, A.Y. and Cossins, A.R. (2006) Hypoxia-Inducible Myoglobin Expression in Nonmuscle Tissues. Proceedings of the National Academy of Sciences of the United States of America, 103, 2977-2981. https://doi.org/10.1073/pnas.0508270103

[20] Huang, L.E., Gu, J., Schau, M. and Bunn, H.F. (1998) Regulation of Hypoxia-Inducible Factor 1alpha Is Mediated by an $\mathrm{O}_{2}$-Dependent Degradation Domain via the Ubiquitin-Proteasome Pathway. Proceedings of the National Academy of Sciences of the United States of America, 95, 7987-7992.

https://doi.org/10.1073/pnas.95.14.7987 